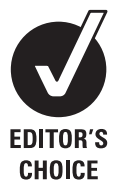

For numbered affiliations see end of article

\section{Correspondence to}

Professor Lars Engebretsen, University of Oslo/ IOC Medicaly Scientific Department, Orthopaedic Surgery, Kirkeveien 111,

Oslo 0407, Norway: lars.engebretsen@ medisin.uio.no

Received 17 April 2012 Accepted 23 April 2012

Published Online First 9 June 2012

\title{
International Olympic Committee consensus statement on thermoregulatory and altitude challenges for high-level athletes
}

\author{
MF Bergeron, ${ }^{1,2}$ R Bahr, ${ }^{3}$ P Bärtsch, ${ }^{4}$ L Bourdon, ${ }^{5} \mathrm{JAL}$ Calbet, ${ }^{6} \mathrm{KH}$ Carlsen, ${ }^{7-9}$ \\ 0 Castagna, ${ }^{5} \mathrm{~J}$ González-Alonso, ${ }_{10}^{10} \mathrm{C}$ Lundby, ${ }^{11}$ RJ Maughan, ${ }^{12} \mathrm{G} \mathrm{Millet}^{13}$ \\ M Mountjoy, ${ }^{14-16}$ S Racinais, ${ }^{17}$ P Rasmussen, ${ }^{11,18}$ DG Singh, ${ }^{19-21}$ AW Subudhi, ${ }^{22}$ \\ AJ Young, ${ }^{23}$ T Soligard, ${ }^{24}$ L Engebretsen ${ }^{24}$
}

\section{ABSTRACT}

Challenging environmental conditions, including heat and humidity, cold, and altitude, pose particular risks to the health of Olympic and other high-level athletes. As a further commitment to athlete safety, the International Olympic Committee (IOC) Medical Commission convened a panel of experts to review the scientific evidence base, reach consensus, and underscore practical safety guidelines and new research priorities regarding the unique environmental challenges Olympic and other international-level athletes face. For non-aquatic events, external thermal load is dependent on ambient temperature, humidity, wind speed and solar radiation, while clothing and protective gear can measurably increase thermal strain and prompt premature fatigue. In swimmers, body heat loss is the direct result of convection at a rate that is proportional to the effective water velocity around the swimmer and the temperature difference between the skin and the water. Other cold exposure and conditions, such as during Alpine skiing, biathlon and other sliding sports, facilitate body heat transfer to the environment, potentially leading to hypothermia and/ or frostbite; although metabolic heat production during these activities usually increases well above the rate of body heat loss, and protective clothing and limited exposure time in certain events reduces these clinical risks as well. Most athletic events are held at altitudes that pose little to no health risks; and training exposures are typically brief and well-tolerated. While these and other environment-related threats to performance and safety can be lessened or averted by implementing a variety of individual and event preventative measures, more research and evidence-based guidelines and recommendations are needed. In the mean time, the IOC Medical Commission and International Sport Federations have implemented new guidelines and taken additional steps to mitigate risk even further.

\section{INTRODUCTION}

Protecting the health of Olympic athlete is the highest priority of the International Olympic Committee (IOC) Medical Commission. ${ }^{1}$ Emphasising this commitment, an injury surveillance system was established for all team sports during the 2004 Athens Olympic Games. ${ }^{2}$ This was followed by including individual sports in the IOC injury surveillance system, beginning with the 2008 Beijing games. ${ }^{3}$ For the 2010 Vancouver winter games, the surveillance system was expanded to include newly sustained illnesses. ${ }^{4}$

Challenging environmental conditions, including heat and humidity, cold, and altitude, pose particular risks to the health of the athlete. As athletes must also contend with the unique physical requirements of their respective sport, universal safety guidelines do not always sufficiently address sport-specific injury and other clinical risks. The interaction between the demands of the sport and the environmental conditions even with seemingly benign environments that represent limited danger to the general population under less intense and/or shorter recreational scenarios - can present a substantial potential hazard to the health of the Olympic athlete or other elite athlete who is making an all-out effort for an extended period of time. For example, exertional heatstroke has been reported in a marathon runner recovering from a viral syndrome during a race held in a cool $\left(6.1-9.4^{\circ} \mathrm{C}\right)$ but humid $(62-99 \%$ relative humidity - RH) environment. ${ }^{5}$ Conversely, during a $21 \mathrm{~km}$ event in warm and humid conditions (WBGT $26.0-29.2^{\circ} \mathrm{C}$ ), all runners finished the race without symptoms of exertional heat illness, despite body core temperature being $>39^{\circ} \mathrm{C}$ for all of the 18 screened runners. Moreover, 10 of those asymptomatic screened finishers had a body core temperature $>40^{\circ} \mathrm{C}$, while two reached $41^{\circ} \mathrm{C} .{ }^{6}$ Notably, a number of individual factors (eg, experience, recent health history and status, fitness, acclimatisation, physical and psychological make-up, nutritional and hydration status and sweat loss rate) each play a key role in the athlete's capacity to adequately adapt to and safely tolerate new and demanding environments, thus making it even more challenging to develop and implement universally effective safety guidelines.

In recognition of these realities, and to further enhance the IOC Medical Commission's commitment to athlete safety, a panel of experts convened in December 2011 to review the scientific evidence base, reach consensus and underscore practical safety guidelines and new research priorities for sports governing bodies, event organisers, medical support teams, coaches and athletes regarding the unique environmental challenges Olympic and other international-level athletes face. Key questions presented to the panel included the following: what are the clinical risks to athletes during 
training and competing in challenging environments? what are the safe environmental limits for training and competition? what are the best methods to prepare for and adapt to environmental challenges? what additional practical preventive measures can be put in place to further minimise healthrelated environmental risks? The expert panel systematically addressed these issues and provides here updated safety and research recommendations, based on the latest scientific and clinical evidence.

This consensus article is not intended to be a comprehensive review of environmental challenges and inclusive of all recommended safety procedures for training and competing in adverse climates. Rather, the intent is to highlight selected key environment-related risk factors that continue to challenge Olympic and other international-level athletes. The other priority is to re-emphasise and provide additional recommendations to address and minimise those risks associated with recent and ongoing incidents of environmentally prompted illness, injury and death in sport.

\section{EFFECTS OF HEAT STRESS ON HEALTH AND PERFORMANCE OF HIGH-LEVEL ATHLETES}

\section{Environmental factors contributing to hyperthermia}

External thermal load is dependent on ambient temperature, humidity, wind speed and solar radiation, and it is generally estimated by the Wet-Bulb-Globe-Temperature (WBGT) index. All of these contributing environmental factors are included in calculating WBGT from the dry (standard thermometer) temperature, the wet-bulb temperature (which indicates the true capacity of the air to evaporate water according to its RH and velocity) and the solar radiation (globe temperature). WBGT indicates the temperature of a saturated immobile air which would impose the same thermal load as the actual environment. In hot conditions, conductive heat exchange between air and skin is usually minimal because the temperature difference (ie, temperature gradient between the environment and skin or vice versa) is typically small. Notably, humidity of air plays a major role in exertional heat illness risk, particularly in hot conditions. During exercise in the heat, excessive body heat is primarily lost through evaporation of sweat at the surface of skin. If the humidity is high, the water vapour pressure of air will be high, and consequently sweating is much less effective in releasing body heat because evaporation is inhibited. ${ }^{7}$ Wind speed is also important given that wind can enhance heat transfer from the skin; moreover, the moving air readily replaces the skin surface air that has been enriched by evaporating water with more dry air which encourages further sweat evaporation. Certain events with an inherent elevated speed (eg, cycling) will not be affected by high heat and humidity to the same extent as sports where the body moves very little or at much lower speeds (eg, athletics, beach volleyball), because the heat release increases with wind flow and an increase in ambient temperature decreases air density and aerodynamic resistance. ${ }^{89}$ Lastly, infrared light from the sun (solar radiation) must also be considered, as this can be a measurable heat source to the surface of the body and often burn the skin. Sunburn can exacerbate thermal sensation during exercise and limit thermoregulation, through a locally mediated effect on sweat gland responsiveness and capacity. ${ }^{10}$

In water, body heat loss is the direct result of convection between skin and water at a rate determined by the convective heat transfer coefficient that is proportional to the speed of water and the temperature difference between the skin and water; accordingly, it is therefore generally accepted that swimmers will not incur hyperthermia in water below $31^{\circ} \mathrm{C}$. However, at all water temperatures, the thermal properties and design of swimmers' garments are of tremendous importance for maintaining thermal balance. Unfortunately, empirical data from the laboratory and field to clarify the specific effects of practical water temperature ranges on athletes are limited.

For all non-aquatic events, clothing and protective gear can measurably increase thermal strain, especially in the heat. The negative impact is particularly pronounced in certain sports, such as equestrian or cycling BMX, because of the protective functional design which can greatly interfere with sweat evaporation. These effects on thermal strain to athletes must be taken into consideration in each specific sport, as modifications to legal protective gear and performance clothing are not easily implemented.

\section{Physiological challenges during training and competition in a hot environment}

Physical and sport performance across a diverse and wide range of athletic activity, duration and intensity can be severely impaired during training and competition in hot environments. ${ }^{11}$ This impairment is manifested by an inability to maintain strength, power, speed, endurance, and consequently sport-specific neuromotor skill performance, prompted by premature fatigue as a result of a complex process involving multiple physiological systems and mechanisms. Sport training and competition in hot environments can pose severe challenges to cardiovascular, thermoregulatory, metabolic, neural and cognitive function, as well as yield a much greater perception of effort. ${ }^{12-17}$ The magnitude of the deleterious effects of heat stress on performance depends on the sport discipline; but generally, physiological strain typically increases with protracted sustained effort as the duration of a training session or competition progresses. Unsustainable physical activity in severe heat stress leading to hyperthermic fatigue and exhaustion is characterised by marked dehydration and progressive concomitant reductions in stroke volume, brain and active muscle blood flow (secondary to hypotension) and systemic, muscle and brain oxygen delivery coupled with augmented brain metabolism, substrate depletion and a progressive increase in body core and brain temperatures. If unchecked, this progression can lead to heat exhaustion and, in extreme cases, life-threatening exertional heatstroke during endurance and high-intensity activities characteristic of many summer Olympic sports.

\section{Modifiable factors to minimise risk of hyperthermia and exertional heat illness \\ Hydration}

Sufficient hydration prior to, during, and in recovery is integral to athletic performance and safety during training and competition in the heat. However, because there are large interpersonal and sport-specific variations in fluid loss, ${ }^{18}$ it is difficult to provide universal recommendations on adequate fluid intake. Pre to postexercise changes in body weight, as well as urine colour and volume, can help athletes to effectively assess fluid loss through sweating and estimate hydration status. ${ }^{19}$ Importantly, public health recommendations regarding dietary salt intake (eg, <6 g per day) may not always apply to elite athletes. Specific monitoring of daily sodium homeostasis (consumption vs sweat losses) and deliberately increasing salt intake before, throughout 
and after training and sporting events to maintain sodium balance and help retain and distribute ingested water, especially in a thermally stressing environment when sweating and concomitant losses of electrolytes are extensive, is often necessary. ${ }^{20}$

\section{Acclimatisation}

Heat acclimatisation usually refers to the progressive physiological adaptations achieved to improve exercise-heat tolerance and safety by exercising in natural outdoor hot ambient conditions; whereas heat acclimation refers to an indoor laboratory protocol to obtain similar adaptive effects. ${ }^{21}$ Importantly, natural heat acclimatisation is more complete than artificial acclimation, ${ }^{22}$ as it includes other factors beyond physiological heat adaptation, such as learning pacing strategies. Sufficient sport training in a temperate environment provides partial desired adaptations, ${ }^{23}$ but it does not fully replace heat acclimatisation. $^{24}$

A minimum of 1 week (although, just a few days helps) and an optimum of 2 weeks of acclimatisation are the typical recommendations for athletes, before competing in a hotter and/ or more humid environment than they are accustomed to. ${ }^{25}$ However, individual needs and responses are highly variable, ${ }^{26}$ and coaches should customise the heat acclimatisation period and process to each athlete to the extent practical. Several months before a scheduled hot-weather major event, athletes should go through an exercise-heat experience similar to what they expect to encounter, in order to determine their adaptability to the heat and to assist in planning their heat acclimatisation duration and procedure for the weeks immediately preceding the event. Heat acclimatisation progress can be objectively ascertained by a decrease in sweat sodium concentration, as well as an increase in sweat rate, a decrease in core body temperature and a decrease in heart rate in response to a standard exercise protocol in the heat; ${ }^{27-29}$ although these changes are not always measurably realised. When possible, team physicians can also measure the change in plasma volume before, during and after heat acclimatisation, to predict the ability of elite athletes to cope with the heat in competitive situations, and individualise their preparation accordingly. ${ }^{26}$ Successful heat acclimatisation increases work capacity in hot and neutral environments ${ }^{29-32}$ and reduces exertional heat illness risk.

\section{Warm-up and precooling}

Warm-up is fundamental to athletic performance. One of the main objectives of the warm-up period is to increase muscle temperature and promote dilation of capillaries to increase perfusion and oxygen transport to the muscles. When carried out under hot conditions, warm-up can, however, induce an undesirable level of body heat storage. Accordingly, subsequent physical activity would then begin with a higher body core temperature that could lead to earlier excessive heat strain and reduced performance. This underscores the importance of limiting warm-up intensity and duration during endurance events in hot conditions and providing enough recovery time before the start of competition to rehydrate and restore body core temperature. Precooling the athlete with cold/ice water immersion, ice vests or other garments/devices before physical activity, during the active warm-up and between exercise bouts, in order to reduce baseline body core temperature, has been shown in some experimental settings to enhance performance, especially with aerobic exercise; ${ }^{33}$ but data from actual competitive scenarios are lacking. More recently, ice slurry ingestion before exercise has been shown to be similarly effective as cold water immersion in enhancing performance in a laboratory setting. ${ }^{34}$ Precooling may thus be warranted in warm-to-hot weather conditions, especially prior to longduration physical exertion or between multiple same-day bouts of physical activity to reduce heat strain and enhance performance.

\section{Clothing}

Sports clothing should place minimal restrictions on sweat evaporation, and the naked skin area available for evaporative heat loss should be maximised. Sport federations should thus consider potential hot and humid weather conditions when regulating the competition apparel of their athletes.

\section{Recommendations for sporting organisations and governing bodies for reducing heat illness risk}

Facilities

Event organisers and administrators should provide the best possible facilities and infrastructure for minimising the heat strain imposed on athletes throughout competition, as well as during preparation and recovery times. Such measures include, but are not restricted to, providing air-conditioned meeting rooms and locker rooms for athletes and support staff throughout the event and readily accessible shaded areas to reduce the overall heat exposure, as well as cooling stations on or immediately next to the competition site. A comprehensive emergency action plan should be in place with sufficient trained staff and the capacity for whole-body rapid cooling and body core temperature monitoring of on-site athletes.

\section{Scheduling}

Organisers and sport ruling bodies should allow for rescheduling of events to a time of day where less heat stress and exposure would be expected, as well as allow for longer and more frequent breaks during competition as heat and humidity increase. Time of day can influence athletic performance in other ways as well - for example, sprint performance is reportedly better in the late afternoon than in the morning. ${ }^{35}$ Certain team sports such as running relays or football may benefit similarly. Accordingly, many athletes prefer to compete later in the day. Endurance performance in the heat, however, may benefit from the lower core temperature in the morning. ${ }^{36}$ A passive warm-up effect prompted by a diurnal increase in body temperature that peaks in the late afternoon or a warm-to-hot environment itself (but not both concomitantly) can play a role in enhancing muscle capacity and performance. Consequently, for some events, acute exposure to heat in the morning has the potential to improve the muscle function and can thus allow sprinters, for example, to reach peak performance earlier in the day that might otherwise be more naturally achievable in the late afternoon. ${ }^{37}$ This could assuage concerns of those participating in the qualification rounds scheduled earlier in the day, and might even represent an advantage for these athletes; but such a tactic could also offer more flexibility for the scheduling of a variety of events by the organiser.

\section{Recommendations for research}

While much is known, and myriad protocols have been implemented to improve safety, gaps remain. Accordingly, and recognising that research and resulting recommendations must be sport-specific, the panel recommends new research to:

- Better characterise the sport- and event-specific thermal and cardiovascular strain profiles of Olympic and international- 
level athletes competing in the heat using ingestible temperature sensors ('pills') and other field-expedient monitoring devices.

- Determine evidence-based, sport-specific safety cut-off points (using on-site WBGT or other heat index) for restricting or cancelling competition.

- Develop and implement automated safety-monitoring for recognising and tracking abnormal slowing down of a participant and rapid-response procedures.

- Improve fluid replacement during endurance competition, determine optimum prehydration prior to high-intensity events (eg, 5000 and $10000 \mathrm{~m}$ in athletics), and clarify the best methods for serving specific sports (eg, team sports) with effective strategies for optimising hydration.

- Determine the effectiveness and the best practice for warm-up, precooling and periodic cooling during rest periods for the elite athlete.
- Determine the performance- and safety-related acclimatisation responses of the elite athlete and the mechanism(s) behind the large interindividual variability (eg, genetic basis).

\section{EFFECTS OF COLD EXPOSURE ON HEALTH AND PERFORMANCE OF HIGH-LEVEL ATHLETES}

Effects of a cold environment

Athletes in some Olympic sports are routinely exposed to cold during training and competition (figure 1). Cold exposure facilitates body heat transfer to the environment, potentially leading to hypothermia and/or frostbite, if sufficient body heat is lost. That is, despite behavioural and physiological responses acting to preserve body temperature, core or peripheral skin temperatures can decline to critical levels, where normal metabolism and physiological function are compromised and skin and other tissue damage occurs. ${ }^{38}$ Environmental cooling

\begin{tabular}{|c|c|c|c|c|c|c|c|c|c|c|c|c|}
\hline \multicolumn{13}{|c|}{ Actual Air Temperature $\mathrm{T}_{\text {air }}\left({ }^{\circ} \mathrm{C}\right)$} \\
\hline \begin{tabular}{|c|} 
Wind \\
Speed \\
$v_{10 \mathrm{~m}}(\mathrm{~km} / \mathrm{h})$
\end{tabular} & 5 & 0 & -5 & -10 & -15 & -20 & -25 & -30 & -35 & -40 & -45 & -50 \\
\hline 5 & 4 & -2 & -7 & -13 & \begin{tabular}{|l|}
-19 \\
\end{tabular} & \begin{tabular}{|l|}
-24 \\
\end{tabular} & -30 & \begin{tabular}{|l|}
-36 \\
\end{tabular} & -41 & -47 & -53 & -58 \\
\hline 10 & 3 & -3 & -9 & -15 & \begin{tabular}{|l|}
-21 \\
\end{tabular} & \begin{tabular}{|l|}
-27 \\
\end{tabular} & -33 & -39 & -45 & -51 & -57 & -63 \\
\hline 15 & 2 & -4 & -11 & -17 & \begin{tabular}{|l|}
-23 \\
\end{tabular} & -29 & -35 & -41 & -48 & -54 & -60 & -66 \\
\hline 20 & 1 & -5 & -12 & -18 & \begin{tabular}{|l|}
-24 \\
\end{tabular} & \begin{tabular}{|l|}
-30 \\
\end{tabular} & -37 & -43 & -49 & -56 & -62 & -68 \\
\hline 25 & 1 & -6 & -12 & -19 & \begin{tabular}{|l|}
-25 \\
\end{tabular} & \begin{tabular}{|l|}
-32 \\
\end{tabular} & -38 & \begin{tabular}{|l|}
-44 \\
\end{tabular} & -51 & -57 & -64 & -70 \\
\hline 30 & 0 & -6 & -13 & -20 & \begin{tabular}{|l|}
-26 \\
\end{tabular} & \begin{tabular}{|l|}
-33 \\
\end{tabular} & -39 & -46 & -52 & -59 & -65 & -72 \\
\hline 35 & 0 & -7 & -14 & -20 & \begin{tabular}{|l|}
-27 \\
\end{tabular} & \begin{tabular}{|l|}
-33 \\
\end{tabular} & -40 & -47 & -53 & -60 & -66 & -73 \\
\hline 40 & -1 & -7 & -14 & -21 & \begin{tabular}{|l|}
-27 \\
\end{tabular} & \begin{tabular}{|l|}
-34 \\
\end{tabular} & -41 & \begin{tabular}{|l|}
-48 \\
\end{tabular} & -54 & -61 & -68 & -74 \\
\hline 45 & -1 & -8 & -15 & -21 & \begin{tabular}{|l|}
-28 \\
\end{tabular} & \begin{tabular}{|l|}
-35 \\
\end{tabular} & -42 & \begin{tabular}{|l|}
-48 \\
\end{tabular} & -55 & -62 & -69 & -75 \\
\hline 50 & -1 & -8 & -15 & -22 & -29 & -35 & -42 & -49 & -56 & -63 & -69 & -76 \\
\hline 55 & -2 & -8 & -15 & -22 & \begin{tabular}{|l|}
-29 \\
\end{tabular} & -36 & -43 & -50 & -57 & -63 & -70 & -77 \\
\hline 60 & -2 & -9 & -16 & -23 & -30 & -36 & -43 & -50 & -57 & -64 & -71 & -78 \\
\hline 65 & -2 & -9 & -16 & -23 & \begin{tabular}{|l|}
-30 \\
\end{tabular} & -37 & -44 & -51 & -58 & -65 & -72 & -79 \\
\hline 70 & -2 & -9 & -16 & -23 & \begin{tabular}{|l|}
-30 \\
\end{tabular} & -37 & -44 & -51 & -58 & -65 & -72 & -80 \\
\hline 75 & -3 & -10 & -17 & -24 & \begin{tabular}{|l|}
-31 \\
\end{tabular} & \begin{tabular}{|l|}
-38 \\
\end{tabular} & -45 & \begin{tabular}{|l|}
-52 \\
\end{tabular} & -59 & -66 & -73 & -80 \\
\hline 80 & -3 & -10 & -17 & -24 & \begin{tabular}{|l|}
-31 \\
\end{tabular} & -38 & -45 & \begin{tabular}{|l|}
-52 \\
\end{tabular} & -60 & -67 & -74 & -81 \\
\hline & & & & & stbite & Guid & & & & & & \\
\hline & & & ow ris & $k$ of $\mathrm{fr}$ & ostbite & for $m$ & ost p & ople & & & & \\
\hline Increas & $\operatorname{lg~ri}$ & of $\mathrm{fr}$ & stbite & for $m$ & ost pe & ople n & vithin & $30 \mathrm{mir}$ & utes & of exp & sure & \\
\hline & High & isk fo & $\mathrm{mos}$ & peop & e in 5 & to 10 & $\min u$ & es of & expos & & & \\
\hline & & risk $\mathrm{f}$ & $\mathrm{rmos}$ & t peo & ole in 2 & 2 to 5 & minut & es of $t$ & xpost & & & \\
\hline & & & $a a^{2}$ & 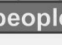 & e in 2 & minut & es & $\exp$ & sure & 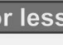 & & \\
\hline
\end{tabular}

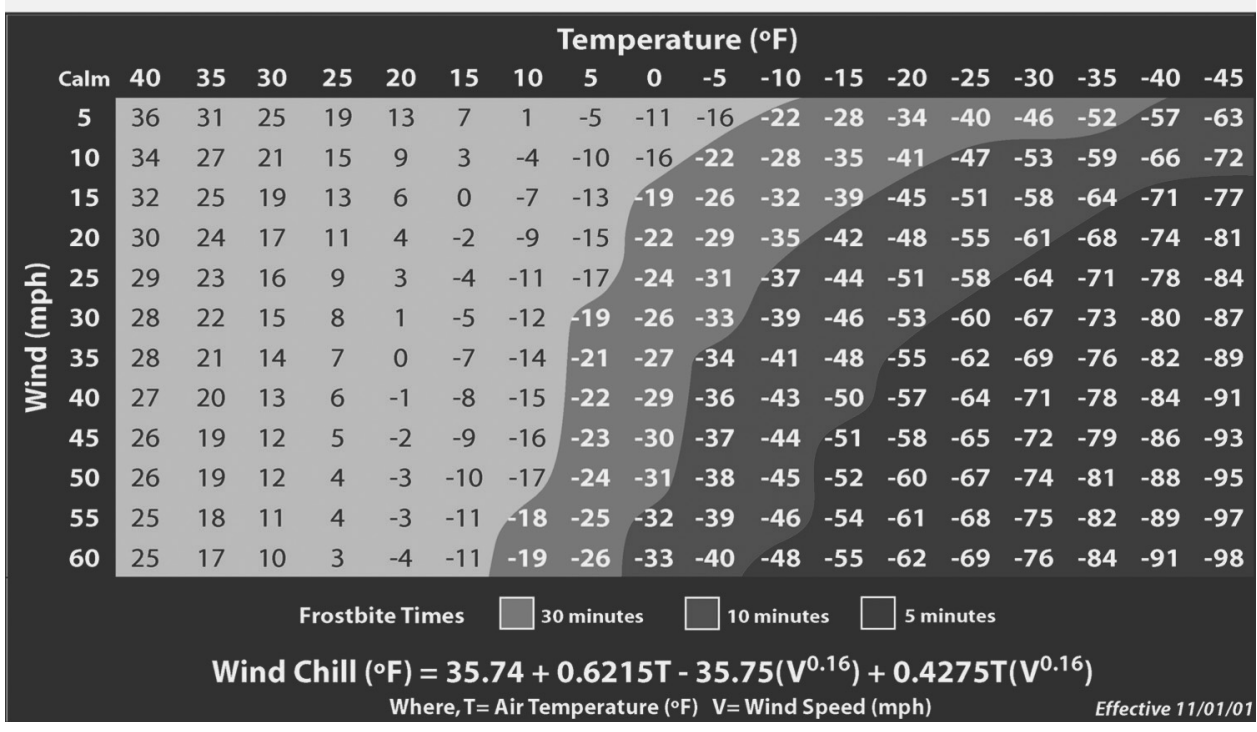

Figure 1 Windchill temperature index in Celsius ${ }^{46}$ and Fahrenheit. ${ }^{47}$ Frostbite times are for exposed facial skin. 
power is not only determined by the ambient temperature, but also by wind, which facilitates convective heat loss, and wet clothing, which in turn increases evaporative heat loss. ${ }^{8}$ Water temperature and current can have significant cooling effects as well. Moreover, inhalation of cold air, especially during physical activity, can have additional adverse health effects both for asthmatic and healthy athletes.

\section{Hypothermia and sports}

During the past three winter Olympics, ambient temperatures have ranged from -5 to $+8^{\circ} \mathrm{C}$. However, metabolic heat production during exercise usually increases well above the rate of body heat loss in such and even colder air temperatures. ${ }^{39}$ For example, during Alpine skiing and other sliding sports, athletes can be exposed to considerable cold (low-air temperature and wind). But metabolic heat production during these activities is very high (6-11 METS, 600-1000 W), and each run during these events is completed in 3 min or less. Such brief cold exposures, coupled with such high-metabolic rates, almost certainly eliminate any risk of hypothermia during competition. ${ }^{38}$ And while some Nordic skiing and biathlon events require $2 \mathrm{~h}$ to complete, metabolic heat production during these activities is even higher, often reaching 13-18 METS (1250-1800 W). ${ }^{40} 41$ So, despite longer exposures, these very high-metabolic rates will offset heat loss and prevent athletes from developing hypothermia during competition in conditions typifying the past three winter Olympics, and probably even with much more extreme cold conditions. ${ }^{41}$

The Olympic summer games include a $10 \mathrm{~km}$, open-water swimming event. Body heat loss during water immersion can be many times that incurred during exposure to air of the same temperature, raising concern regarding hypothermia during open-water swimming. 83839 However, the guidelines of the governing body for aquatics, Fédération Internationale de Natation (FINA), specify that the lower limit for water temperature (measured $1 \mathrm{~m}$ below the surface) is $16^{\circ} \mathrm{C}$. If water temperature is lower, the event will be cancelled. Thermoregulatory modelling suggests that male and female open-water swimmers will not likely experience dangerous declines in body temperature in water temperatures of $16^{\circ} \mathrm{C}$ and higher when swimming at typical competition speeds. ${ }^{42}$ However, selfreports from athletes of perceived functional limitations from cold water resulting in widespread non-finishes at a recent international open-water championships event (Quebec, 2010), when the water temperature was at $16^{\circ} \mathrm{C}$ lower limit, underscore the need for research examining the appropriateness of this specific federation cancellation threshold.

A potential arrhythmogenic effect of water is another concern for swimmers. The combination of cold water exposure, voluntary apnoea and face immersion may result in increased sympathetic and parasympathetic activity, possibly causing ventricular premature beats. ${ }^{43}$ Accordingly, cold water itself could be a contributing factor to fatal events in open-water swimming.

\section{Frostbite and sports}

Frostbite occurs when tissue temperatures fall below $0{ }^{\circ} \mathrm{C} .384445$ Notably, wind increases convective heat loss at exposed skin and increases the risk of frostbite. This is the basis of the commonly reported 'windchill' equivalent temperature (figure 1). In addition, running and skiing produce wind across the body, adding to the windchill. When the windchill equivalent temperature falls below $-27^{\circ} \mathrm{C}$, frostbite can occur in $30 \mathrm{~min}$ or less at exposed skin. ${ }^{38}$ During Nordic skiing and biathlon, competitors achieve speeds of $24-27 \mathrm{~km} / \mathrm{h}$. At that wind speed, air temperature must be $-20^{\circ} \mathrm{C}$ or colder to create a risk of frostbite. However, during certain Alpine skiing and sliding events, competitors achieve speeds of $60-100 \mathrm{~km} / \mathrm{h}$. At these wind speeds, an air temperature of only $-15^{\circ} \mathrm{C}$ could create a risk of frostbite. Again, however, each run is typically completed in 3 min or less; so frostbite is unlikely to occur at that time. Furthermore, windchill and the risk of frostbite at these temperatures are only applicable for exposed skin; so windproof clothing nearly eliminates that risk. While an individual's performance may only take a few minutes, the entire event itself lasts for many hours during which metabolic activity is substantially lower, if not near rest. Frostbite risk over these prolonged periods, especially for coaches, support staff and officials who may be standing or sitting in the cold, should be considered as well (figure 1).

\section{Cold exposure and respiratory problems in athletes}

Exercise-induced asthma (EIA) and bronchial hyper-responsiveness (BHR) occur in $\geq 50 \%$ of elite cross-country skiers ${ }^{48}$ and swimmers. ${ }^{49}$ EIA is thought to be caused by heat loss ${ }^{50}$ and water loss ${ }^{51}$ through respiration, while inhaled cold air greatly enhances the magnitude of exercise-induced bronchoconstriction $(\mathrm{EIB})^{52}$ and reduces performance. ${ }^{53}$ Cold-facial temperatures increase EIB even if inhaling warm air, ${ }^{54}$ suggesting a parasympathetic nervous reflex. Endurance sports with cold exposure, including cross-country skiing, Nordic skiing combined, biathlon and speed skating, have a high prevalence of asthma and BHR. ${ }^{5}$ The causative factor is thought to be epithelial damage of respiratory mucosa, as shown in animal studies. ${ }^{56}$ Airway inflammation, indicated by per cent neutrophils in induced sputum, is correlated to number of training hours per week in cross-country skiers and swimmers; ${ }^{57}$ while age and number of competitive years in cross-country skiers has been associated with level of BHR. ${ }^{55}$ Furthermore, participation in competitive cross-country skiing over a winter season markedly enhanced airway inflammation in bronchial biopsies in young skiers with and without asthma. ${ }^{58}$ In athletes with positive metacholine BHR compared with negative metacholine BHR, sweat excretion, saliva production and tear flow were markedly reduced, indicating increased parasympathetic activity. ${ }^{59}$ Moreover, increased parasympathetic (vagal) activity was indicated by protection against EIB by inhaled ipratropium bromide in cross-country runners exercising at cold temperatures ${ }^{60}$ and in children with EIB. ${ }^{61}$ Altogether, these studies point to respiratory epithelial damage as the primary contributing factor to respiratory problems in endurance athletes; and this is augmented by cold exposure, thus increasing airway inflammation. Moreover, epithelial bronchial culture cells from asthmatics have been shown to heal more slowly after scarring compared with healthy individuals. However, the healing rate was greatly enhanced by adding steroids to cell culture. ${ }^{62}$

Cutaneous vasoconstriction prompted by cold water exposure can increase venous return, leading to an increase in blood pressure and central vascular volume. Reportedly, this can result in acute pulmonary oedema and hemoptysis in swimmers, similar to swimming-induced or immersion-related pulmonary congestion. ${ }^{63} 64$

\section{Acclimatisation}

The effects of cold acclimatisation in humans are minimal, and provide little, if any practical advantage in terms of preserving normal body temperature and preventing cold injury. 


\section{Cold exposure summary}

Hypothermia and/or frostbite are very unlikely for rested, fit elite athletes wearing wind protective clothing and competing in weather conditions typical of the recent three Winter Olympics, because high-metabolic rates and brief exposures limit body heat losses. A very conservative ambient air temperature limit of $-15^{\circ} \mathrm{C}$ during events could be justified to mitigate frostbite risk. Risk may be higher for athletes during training due to overtraining or fatigue effects, and atypically cold temperatures could increase frostbite risk for Alpine skiing and sliding events due to high speeds (wind) achieved. ${ }^{65-67}$ Although thermoregulatory modelling suggests that hypothermia is unlikely for the athlete swimming in water of $16^{\circ} \mathrm{C}$, field reports indicate that numerous swimmers can suffer from perceived functional limitations, emphasising the need for definitive field-of-play research.

Increased ventilation during repeated physical training and competition, with resulting airway inflammation and increased parasympathetic activity enhanced by cold exposure, is the probable cause of increased prevalence of asthma and BHR in cold weather. Inhaled steroids are important for the healing process and have been shown not to improve the performance in healthy athletes. The athlete asthma phenotype is characterised by the presence of BHR, cough and phlegm. Symptoms occur more frequently after closely repeated competitions, and exacerbations are frequently caused by respiratory viral infections. The first symptoms of asthma often occur when competing with a respiratory tract infection.

\section{Practical recommendations}

For athletes who train and compete in the cold, a number of key practical guidelines can improve comfort and minimise exposure-related clinical risk in these conditions. Key recommendations include:

- Environmental measures:

- Weather conditions (wind, air temperature) should be measured and recorded before and during outdoor events. The site where the weather conditions are measured should be as close as possible to the location where competitors will be most exposed to the weather conditions.

- Standardised charts to compute the effective windchill temperature from air temperature and wind speed should be provided to appropriate officials, and the speed range for competitors in the different winter events should be printed on that same chart and used to compute effective windchill temperature when natural wind speed is less than the speed of the competitor.

- Competitions should be avoided when competitors would be exposed to combinations of air temperature and wind speed (including the speed of the competitor) that achieve an effective windchill temperature colder than $-27^{\circ} \mathrm{C}$.

- Protection equipment for cold air exposure should be used during training at low temperatures.

- It is important to provide regular medical follow-up of elite endurance athletes with cold exposure to detect frostbite, BHR or EIB early.

- Efforts for optimal asthma treatment and monitoring should focus on:

- Early anti-inflammatory treatment (inhaled steroids) (avoid possible adrenal suppression during exercise). ${ }^{68}$
- Necessary bronchodilator treatment before exercise and if needed on regular basis focusing on inhaled anticholinergic treatment. (be aware of possible tolerance development to regular use of inhaled $\beta 2$-agonists). ${ }^{69}$

- Other antiasthmatic treatment as indicated.

- As some asthma treatments are on the World Anti-Doping Agency (WADA) Prohibited List, treating physicians should be aware of the latest WADA recommendations for therapeutic use exemptions (TUE) for those athletes who are subject to antidoping regulations. ${ }^{70}$ From 1st January 2012, only the inhaled $\beta 2$-agonist terbutalin needs TUE; the other commonly used inhaled $\beta 2$-agonists salbutamol, salmeterol and formoterol, as well as all inhaled steroids are no longer on the prohibited list and are thus free for use.

- Athletes participating in open-water swimming events where the water temperature may be cold should ensure that they become familiar with the venue and are exposed to the water ahead of time, and be sure that they participate in a sufficient warm-up.

\section{Recommendations for research}

To further improve safety in cold for all participants, the panel recommends new research to examine:

- Accurate measures of metabolic heat production rates during all cold-weather sport events.

- Prediction modelling to estimate probable body core and exposed skin temperature changes during all cold-weather competitive events, so as to determine a realistic range of ambient conditions that would provide an evidence-based definition of safe and appropriate weather and water temperature limits for competition.

- Using ingestible core temperature 'pills' and other telemetry technology to directly measure body core temperature and other physiological changes during each cold-weather competitive event (real or simulated).

- Respiratory epithelial damage and airway inflammation from cold air exposure that are involved in development of BHR in winter athletes.

- Novel treatment options to prevent respiratory epithelial damage from cold air exposure and promote epithelial repair.

\section{EFFECTS OF ALTITUDE ON HEALTH AND PERFORMANCE OF HIGH-LEVEL ATHLETES}

By conventional definitions of altitude (table 1), ${ }^{71}$ most athletic events are held at altitudes that pose little to no health risks; yet even modest altitudes can affect performance. Decreased barometric pressure at altitude reduces air density and the

Table 1 Characteristics of altitude ranges ${ }^{71}$

\begin{tabular}{|c|c|}
\hline Altitude & Definition \\
\hline $0-500 \mathrm{~m}$ & 'Near sea level' \\
\hline Above $500-2000 \mathrm{~m}$ & $\begin{array}{l}\text { 'Low altitude': minor impairment of aerobic } \\
\text { performance becomes detectable }\end{array}$ \\
\hline Above $2000-3000 \mathrm{~m}$ & $\begin{array}{l}\text { 'Moderate altitude': mountain sickness starts to occur } \\
\text { and acclimatisation is increasingly important for } \\
\text { performance }\end{array}$ \\
\hline Above $3000-5500 \mathrm{~m}$ & $\begin{array}{l}\text { 'High altitude': mountain sickness and acclimatisa- } \\
\text { tion become clinically relevant; performance is } \\
\text { considerably impaired }\end{array}$ \\
\hline Above $5500 \mathrm{~m}$ & $\begin{array}{l}\text { 'Extreme altitude': prolonged exposure leads to } \\
\text { progressive clinical deterioration }\end{array}$ \\
\hline
\end{tabular}


partial pressure of inspired oxygen $\left(\mathrm{PO}_{2}\right)$. These two factors have differential, often opposing, effects on endurance, strength/power and skills necessary for elite level performance. The reduction in $\mathrm{PO}_{2}$ impairs maximum aerobic capacity and endurance performance in sports (eg, distance running and cross country skiing), where little benefit is gained from the reduction in air resistance associated with reduced air density. $^{72}$ Individual decrements in performance are subject to a high degree of sport-specific physiologic variation. For higher velocity sports (eg, speed skating, cycling and sprinting), benefits gained from reduced drag can outweigh limitations in aerobic capacity, resulting in improved performance. ${ }^{73}$ Maximum strength and power (eg, weight lifting) are not affected by altitude, yet repeated bouts of high-intensity efforts (eg, sprinting in team sports) may be more affected. ${ }^{74}$ Since projectile motion (eg, ball sports, throwing, shooting and ski jumping) is altered by reduced air density, specific skills requiring precise timing, accuracy and position may be adversely affected. ${ }^{75}$ The overall effect of altitude is thus sport/event specific.

\section{Cardiovascular and pulmonary system}

During submaximal exercise, cardiac output (Q) and locomotor muscle blood flow are increased, offsetting the reduction in arterial oxygen content. During maximal (and supra-maximal) exercise at moderate altitude, $\mathrm{Q}$ and locomotor muscle blood flow will reach maximum values, which are similar to those observed at sea level. ${ }^{76-78}$ The blood pressure response during exercise in acute moderate hypoxia is comparable with that observed during exercise at sea level, and consequently the $\mathrm{O}_{2}$ demand of the heart is the same as well. However, there is no indication of reduced myocardial contractility during maximal exercise, even at a higher altitude. ${ }^{79} 80$ Consequently, the cardiovascular risks incurred during exercise at moderate altitude can be considered similar to those assumed during the same exercise modes at sea level. The only particular difference may be represented by the few elite endurance athletes having severe exercise-induced arterial hypoxaemia at sea level. These athletes may develop more severe hypoxaemia at mild altitude; 81 but there is currently no evidence of increased cardiovascular risk for elite athletes exercising at moderate altitude. As a caution, individuals (eg, coaches and other support staff) with cardiovascular or pulmonary diseases who are accompanying athletes travelling to moderate or high altitude ought to seek medical advice.

\section{Acute mountain sickness}

Acute exposure of non-acclimatised individuals to moderate altitude may lead to acute mountain sickness (AMS), which is a self-limiting condition comparable with having a 'hang-over' or migraine attack. ${ }^{82}$ It can be treated by rest and prevented by slow (staged) ascent or preceding exposures (preacclimatisation). ${ }^{83}$ The prevalence of AMS is $0-25 \%$ at moderate altitude, depending on the individual susceptibility. ${ }^{84}$ Severe obesity and pulmonary disease are additional risk factors for AMS that may be relevant for accompanying staff. AMS prevalence is not different between normobaric and hypobaric hypoxia at the same ambient $\mathrm{PO}_{2}{ }^{85} 86$ Living or sleeping at moderate altitude for $8-16$ h/day does not cause discomfort attributable to hypoxia. ${ }^{87}$ Moreover, exposures over a few minutes to $2-3 \mathrm{~h}$ to more severe hypoxia (equivalent to 5000-6000 $\mathrm{m}$ above sea level) are too short to cause AMS and are well tolerated by healthy athletes at rest and during exercise. Life-threatening high-altitude pulmonary and cerebral oedema rarely occur below 3000 and $4000 \mathrm{~m}$ above sea level, respectively, and only after several days of exposure, and therefore are not concerns at altitudes where most competitions are carried out. ${ }^{88}$

\section{Preparation and other considerations for events held at low and moderate altitudes}

The key factor in reducing clinical risk and optimising performance is to arrive to the site of competition or to a site of equivalent altitude some time well ahead of the actual event. ${ }^{89}$ Arriving 2 weeks before competition at moderate altitude and allowing 1 or 2 days of rest beore taking up regular training, is the typical recommended approach. At moderate altitude, most athletes will acclimatise within 2 weeks. Partial acclimatisation leading to improved performance can be achieved within 5-7 days, but some individuals may need more time. For acclimatisation at lower altitudes, less time may be sufficient. It is not clear whether modalities such as training in hypoxia while living in normoxia or 'live high and train low' are beneficial for elite athletes competing at moderate altitude. An acclimatisation period over about 2 weeks is also important for sports which are affected by low-air density, as emphasised in the segment (above) on performance. ${ }^{88}$

\section{Nutrition}

Haemoglobin concentration increases acutely with altitude exposure because of diuresis and over time by increased erythropoiesis. At moderate altitude, the diuretic response is small and may not be noticed. In athletes with poor-iron status, erythropoiesis is likely to be impaired. ${ }^{91}$ Therefore, athletes should be checked for serum ferritin about 8-10 weeks prior to exposure to moderate altitude for training or competition. Based on the current evidence, athletes are often advised to increase their dietary iron intake or receive iron supplementation orally when serum ferritin values are less than $30 \mu \mathrm{g} / 1$ for women or $40 \mu \mathrm{g} / 1$ for men. ${ }^{92}$

\section{Hypoxia for improvement of performance near sea level}

Placebo-controlled double-blind studies show that passive exposure to hypoxia over several hours does not improve aerobic or anaerobic performance. ${ }^{93-95}$ Whether training in hypoxia while living in normoxia is superior to training in normoxia for enhancing performance of elite athletes near sea level needs to be investigated in carefully controlled doubleblind studies. Moreover, the purported performance gain by living at simulated moderate altitude and training at low altitude $^{91}$ has been challenged recently. ${ }^{96}$

\section{Recommendations for research}

Specific to the effects of altitude on athlete health and performance, the panel recommends future investigations to:

- Study the effects of training in hypoxia and live high, train low modalities on performance at sea level and low and moderate altitude using a placebo-controlled double-blind design.

- Determine the effect of duration of altitude acclimatisation on performance: how many days does it take to achieve maximal improvement of performance at a particular altitude?

- Obtain high-quality (invasive) data on the cardiovascular response to exercise at low and moderate altitude in elite athletes.

- Investigate the combination of heat, cold and competition stress on performance or AMS at low and moderate altitude. 


\section{INTERNATIONAL SPORT FEDERATIONS: RECOGNISING THE RISKS}

Epidemiological data from the USA show that an estimated 5946 persons were treated in US emergency departments each year during 2001-2009 for exertional heat illness incurred while participating in a sport or recreational activity. ${ }^{97}$ According to the Annual Survey of (American) Football Injury Research, 132 fatalities have been documented from exertional heatstroke from 1931 through 2009, and between two and five cases per year in recent years. ${ }^{98}$ In cycling at the 2002 Argus Cycle Tour in South Africa, five deaths from exertional heatstroke were reported. ${ }^{99}$ These data show that there is a measurable risk of severe exercise/heat-related illness and injury in certain sports. It should be noted, however, that most participants in these studies are adolescent, collegiate or recreational athletes. Accordingly, there is limited reported evidence to date indicating a high-exertional heat illness risk among athletes during Olympic or other competitive events at the world championship level. However, this neither confirms a lack of risk nor mitigates the need to comprehensively examine heatrelated challenges and provide standards to further minimise potential exertional heat illness risk - even with these elite international-level athletes.

Accordingly, international federations have responded to the environmental challenges and health risks in sport. For example, although there is no record of heat-related deaths in elite football or beach volleyball, the Fédération Internationale de Football Association (FIFA) and the Fédération Internationale de Volleyball (FIVB) have established guidelines to avoid the scheduling of matches during the hottest periods of the day to reduce exertional heat illness risk to the players. Other measures include allowing cooling breaks (in the 2008 Olympic Games men's football final, cooling breaks were introduced at 30 and $75 \mathrm{~min}$ ), permitting more frequent side changes or timeouts (used on the FIVB beach volleyball World Tour to allow players to rest and rehydrate). Also, plenty of ice, cold towels, cool mist spray and water/rehydration fluids are readily available to encourage athlete cooling. Another key preventive measure is systematic monitoring of the environmental conditions. In certain sports, including marathon running and FIFA and FIVB competitions, WBGT recordings are used to guide decisions on implementing additional on-site measures to improve the safety of athletes.

With cold-weather competition, winter sports federations such as the Fédération Internationale de Ski (FIS) closely monitor air temperature and wind, in order to make the most appropriate recommendations on limiting cold exposure for these athletes, so as to minimise the risk of hypothermia, frostbite and other cold-related problems. Both the Nordic skiing events as well as biathlon have enforced temperature limitations on organisers of World Cup races; and many national federations have even more all-encompassing rules and measures to limit cold exposure.

Another venue of recognised concern is with marathon swimming, where there are unique environmental challenges and safety concerns in the open water posed by the weather, currents and tides, pollutants and flora and fauna. In response to these environmental threats, FINA has instituted changes to protect health and safety of the swimmer. For example, low- and high-temperature limits have been added to the rules and recommendations, respectively, to ensure that athletes are not exposed to potentially dangerous extremes in water temperatures. In addition, strict water quality protocols and emergency procedures ensuring athlete safety have been instituted.
While altitude appreciably increases physiological strain, inhibits performance, and prompts a variety of clinical symptoms in unprepared and unacclimated individuals, elite athletes rarely compete in settings higher than $2000 \mathrm{~m}$ above sea level. However, myriad athletes regularly use altitude training above this level to improve performance at low or moderate altitude. Accordingly, guidelines and measures to improve altitude acclimatisation, tolerance, and safety have been reviewed and warrant additional attention. ${ }^{75}$

\section{OVERALL CONSENSUS - WHAT ELSE CAN BE DONE?}

While physiology and medicine have been looking after both healthy and pathological organisms for centuries, exercise physiology is a relatively young subdiscipline. The physiology of the exercising human has been primarily studied from occupational, military and laboratory situations. Therefore, there is a clear need for sports federations, team doctors and researchers to collaborate in obtaining much more data and publishing the findings on the specific population of elite athlete. The challenge is now to move from the knowledge of the 'standard human physiological responses' to determining and considering the specific characteristics, responses and behaviour of the elite athlete training and competing across the breadth of encountered environmental extremes.

Accordingly, the panel applauds the IOC Medical Commission's and International Sport Federations' demonstrated commitments to athlete safety. However, we urge the Commission and Federations leaders to assertively and openly press further in their pursuit to better appreciate, closely monitor and appropriately respond to the health and safety challenges in all sport venues, so every Olympic and international-level athlete is adequately protected and thus given the opportunity to demonstrate optimal athletic performance.

Acknowledgements The group acknowledges the contribution of IOC Medical Commission Chairperson, Arne Ljungqvist, and IOC Medical and Scientific Director, Patrick Schamasch during the IOC Consensus Meeting.

\section{Competing interests None.}

Provenance and peer review Commissioned; externally peer reviewed.

\section{Author affiliations}

${ }^{1}$ National Youth Sports Health \& Safety Institute, USA;

2Department of Paediatrics, Sanford School of Medicine of The University of South Dakota, Sanford Children's Health Research Center, Sioux Falls, SD, USA;

${ }^{3}$ Oslo Sports Trauma Research Center, Department of Sports Medicine, Norwegian School of Sport Sciences, Oslo, Norway

${ }^{4}$ Department of Internal Medicine, Division VII: Sports Medicine, University Hospital, Heidelberg, Germany

${ }^{5}$ Institut de recherche biomedicale de defense - Ecole du Val-de-Grace (IRBAEVDG), Paris, France

${ }^{6}$ Department of Physical Education, University of Las Palmas de Gran Canaria, Las Palmas de Gran Canaria, Spain

${ }^{7}$ Faculty of Medicine, University of Oslo, Oslo, Norway

${ }^{8}$ Norwegian School of Sport Sciences, Oslo, Norway

${ }^{9}$ Department of Paediatrics, Rikshospitalet, Oslo University Hospital, Oslo, Norway

${ }^{10}$ Centre for Sports Medicine and Human Performance, Brunel University, Uxbridge, United Kingdom

${ }^{11}$ ZIHP and Institute of Physiology, University of Zurich, Zurich, Switzerland

${ }^{12}$ School of Sport, Exercise and Health Sciences, Loughborough University, Loughborough, United Kingdom

${ }^{13}$ ISSUL Institute of Sport Sciences, Department of Physiology, Faculty of Biology and Medicine, University of Lausanne, Lausanne, Switzerland

${ }^{14}$ Medical Commission, Fédération Internationale de Natation, Lausanne,

Switzerland

${ }^{15}$ Medical Commission, International Olympic Committee, Lausanne, Switzerland

${ }^{16}$ McMaster University, Hamilton, Canada

${ }^{17}$ ASPETAR, Qatar Orthopaedic and Sports Medicine Hospital, Research and Education Centre, Doha, Qatar

${ }^{18}$ Department of Neuroscience and Pharmacology, University of Copenhagen, Copenhagen, Denmark 
${ }^{19}$ Medical Committee, Fédération Internationale de Football Association, Zurich, Switzerland

20Medical Commission, Badminton World Federation, Kuala Lumpur, Malaysia

${ }^{21}$ Medical Committee, Asian Football Confederation, Bukit Jalil, Kuala Lumpur, Malaysia

22Department of Biology and Altitude Research Center, University of Colorado, Colorado Springs and Anschutz Medical Campuses, USA

${ }^{23}$ Military Nutrition Division, US Army Research Institute of Environmental

Medicine, Natick, MA, USA

${ }^{24}$ Medical \& Scientific Department, International Olympic Committee, Lausanne, Switzerland

\section{REFERENCES}

1. Rogge J. An ounce of prevention? Br J Sports Med 2009;43:627.

2. Junge A, Langevoort G, Pipe A, et al. Injuries in team sport tournaments during the 2004 Olympic Games. Am J Sports Med 2006;34:565-76.

3. Junge A, Engebretsen L, Mountjoy ML, et al. Sports injuries during the Summer Olympic Games 2008. Am J Sports Med 2009;37:2165-72.

4. Engebretsen L, Steffen K, Alonso JM, et al. Sports injuries and illnesses during the Winter Olympic Games 2010. Br J Sports Med 2010;44:772-80.

5. Roberts WO. Exertional heat stroke during a cool weather marathon: a case study. Med Sci Sports Exerc 2006:38:1197-203.

6. Byrne C, Lee JK, Chew SA, et al. Continuous thermoregulatory responses to massparticipation distance running in heat. Med Sci Sports Exerc 2006;38:803-10.

7. Maughan RJ, Otani H, Watson P. Influence of relative humidity on prolonged exercise capacity in a warm environment. Eur J Appl Physiol 2012;112:2313-21.

8. Gagge AP, Gonzalez RR. Mechanisms of Heat Exchange. In: Fregly MJ, Blatteis CM, eds. Handbook of Physiology, Section 4: Environmental Physiology. New York: Oxford University 1996:45-84.

9. Nybo L. Cycling in the heat: performance perspectives and cerebral challenges Scand J Med Sci Sports 2010;20 Suppl 3:71-9.

10. Pandolf KB, Gange RW, Latzka WA, et al. Human thermoregulatory responses during heat exposure after artificially induced sunburn. Am J Physiol 1992;262:R610-16

11. González-Alonso J, Crandall CG, Johnson JM. The cardiovascular challenge of exercising in the heat. J Physiol (Lond) 2008;586:45-53.

12. Montain SJ, Coyle EF. Influence of graded dehydration on hyperthermia and cardiovascular drift during exercise. J Appl Physiol 1992;73:1340-50.

13. González-Alonso J, Calbet JA, Nielsen B. Muscle blood flow is reduced with dehydration during prolonged exercise in humans. J Physiol (Lond) 1998;513 (Pt 3):895-905

14. González-Alonso J Calbet JA. Reductions in systemic and skeletal muscle blood flow and oxygen delivery limit maximal aerobic capacity in humans. Circulation 2003:107:824-30

15. González-Alonso J, Dalsgaard MK, Osada T, et al. Brain and central haemodynamics and oxygenation during maximal exercise in humans. J Physiol (Lond) 2004;557:331-42

16. Racinais S, Gaoua N, Grantham J. Hyperthermia impairs short-term memory and peripheral motor drive transmission. J Physiol (Lond) 2008; $586: 4751-62$

17. Gaoua N, Grantham J, El Massioui F, et al. Cognitive decrements do not follow neuromuscular alterations during passive heat exposure. Int $\mathrm{J}$ Hyperthermia 2011;27:10-19

18. Maughan RJ, Shirreffs SM. Development of individual hydration strategies for athletes. Int J Sport Nutr Exerc Metab 2008:18:457-72.

19. Armstrong LE, Maresh CM, Castellani JW, et al. Urinary indices of hydration status. Int J Sport Nutr 1994:4:265-79.

20. Bergeron MF. Muscle cramps during exercise: is it fatigue or electrolyte deficit? Curr Sports Med Rep 2008;7:S50-S55.

21. Armstrong $\mathbf{L E}$, Maresh $\mathrm{CM}$. The induction and decay of heat acclimatisation in trained athletes. Sports Med 1991;12:302-12.

22. Edholm OG. The physiology of adaptation. Eugen Rev 1966:58:136-42.

23. Piwonka RW, Robinson S, Gay VL, et al. Preacclimatization of men to heat by training. J Appl Physiol 1965;20:379-83.

24. Strydom NB, Wyndham CH, Williams CG, et al. Acclimatization to humid heat and the role of physical conditioning. J Appl Physiol 1966;21:636-42.

25. Grantham J, Cheung SS, Connes P, et al. Current knowledge on playing football in hot environments. Scand J Med Sci Sports 2010;20 Suppl 3:161-7.

26. Racinais S, Mohr M, Buchheit M, et al. Individual responses to short-term heat acclimatisation as predictors of football performance in hot dry environment. Br J Sports Med 2012; (In Press).

27. Glaser EM. Acclimatization to heat and cold. J Physiol (Lond) 1949;110:330-7.

28 Ladell WS. Assessment of group acclimatization to heat and humidity. J Physiol 1951;115:296-312

29. Kobayashi Y, Ando Y, Takeuchi S, et al. Effects of heat acclimation of distance runners in a moderately hot environment. Eur J Appl Physiol Occup Physiol 1980:45:189-98
30. Nielsen B, Hales JR, Strange S, et al. Human circulatory and thermoregulatory adaptations with heat acclimation and exercise in a hot, dry environment. $J$ Physiol (Lond) 1993:460:467-85.

31. Lorenzo S, Halliwill JR, Sawka MN, et al. Heat acclimation improves exercise performance. J Appl Physiol 2010:109:1140-7.

32. Buchheit M, Voss SC, Nybo L, et al. Physiological and performance adaptations to an in-season soccer camp in the heat: associations with heart rate and heart rate variability. Scand J Med Sci Sports 2011;21:e477-85.

33. Ranalli GF, Demartini JK, Casa DJ, et al. Effect of body cooling on subsequent aerobic and anaerobic exercise performance: a systematic review. J Strength Cond Res 2010;24:3488-96.

34. Siegel R, Maté J, Watson G, et al. Pre-cooling with ice slurry ingestion leads to similar run times to exhaustion in the heat as cold water immersion. J Sports Sci 2012:30:155-65.

35. Javierre C, Calvo M, Díez A, et al. Influence of sleep and meal schedules on performance peaks in competitive sprinters. Int J Sports Med 1996;17:404-8.

36. Hobson RM, Clapp EL, Watson P, et al. Exercise capacity in the heat is greater in the morning than in the evening in man. Med Sci Sports Exerc 2009:41:174-80

37. Racinais S. Different effects of heat exposure upon exercise performance in the morning and afternoon. Scand J Med Sci Sports 2010;20 Suppl 3:80-9.

38. Castellani JW, Young AJ, Ducharme MB, et al. American College of Sports Medicine position stand: prevention of cold injuries during exercise. Med Sci Sports Exerc 2006;38:2012-29.

39. Toner MM, McArdle WD. Human thermoregulatory responses to acute cold stress with special reference to water immersion. In: Fregly MJ, Blatteis CM, eds. Handbook of Physiology, Section 4: Environmental Physiology. New York: Oxford University 1996

40. Mygind E, Andersen LB, Rasmussen B. Blood lactate and respiratory variables in elite cross-country skiing at racing speeds. Scand J Med Sci Sports 1994;4:243-51

41. Bergh U, Forsberg A. Cross-country ski racing. In: Shephard RJ, Åstrand PO, eds. Endurance in Sport. John Wiley \& Sons 2000:287-300.

42. $\mathbf{X u} \mathbf{X}$ Turner CA, Santee WR. Survival time prediction in marine environments. $J$ Therm Biol 2011;36:340-5.

43. Marsh N, Askew D, Beer K, et al. Relative contributions of voluntary apnoea, exposure to cold and face immersion in water to diving bradycardia in humans. Clin Exp Pharmacol Physiol 1995:22:886-7.

44. Wilson 0, Goldman RF, Molnar GW. Freezing temperature of finger skin. J Appl Physiol 1976;41:551-8.

45. Danielsson U. Windchill and the risk of tissue freezing. J Appl Physio 1996;81:2666-73.

46. Environment Canada. Wind Chill Chart. Meteorological Society of Canada. http://www.ohcow.on.ca/clinics/windsor/docs/workplaceconcernsseminars/ windchillchart.pdf (accessed 27 March 2012).

47. US National Weather Service. Wind Chill Chart. US National Weather Service. http://www.nws.noaa.gov/om/windchill/ (accessed 27 March 2012).

48. Wilber RL, Rundell KW, Szmedra L, et al. Incidence of exercise-induced bronchospasm in Olympic winter sport athletes. Med Sci Sports Exerc 2000:32:732-7.

49. Stadelmann K, Stensrud T, Carlsen KH. Respiratory symptoms and bronchial responsiveness in competitive swimmers. Med Sci Sports Exerc 2011:43:375-81.

50. Deal EC Jr, McFadden ER Jr, Ingram RH Jr, et al. Role of respiratory heat exchange in production of exercise-induced asthma. J Appl Physiol 1979;46:467-75

51. Anderson SD, Daviskas E. The mechanism of exercise-induced asthma is. J Allergy Clin Immunol 2000;106:453-9.

52. Carlsen KH, Engh G, Mørk M, et al. Cold air inhalation and exercise-induced bronchoconstriction in relationship to metacholine bronchial responsiveness: different patterns in asthmatic children and children with other chronic lung diseases. Respir Med 1998:92:308-15.

53. Stensrud T, Berntsen S, Carlsen KH. Exercise capacity and exercise-induced bronchoconstriction (EIB) in a cold environment. Respir Med 2007;101:1529-36.

54. Zeitoun M, Wilk B, Matsuzaka A, et al. Facial cooling enhances exercise-induced bronchoconstriction in asthmatic children. Med Sci Sports Exerc 2004:36:767-71.

55. Stensrud T, Mykland KV, Gabrielsen K, et al. Bronchial hyperresponsiveness in skiers: field test versus methacholine provocation? Med Sci Sports Exerc 2007;39:1681-6.

56. Davis MS, McKiernan B, McCullough S, et al. Racing Alaskan sled dogs as a model of 'ski asthma'. Am J Respir Crit Care Med 2002:166:878-82.

57. Bougault V, Turmel J, St-Laurent J, et al. Asthma, airway inflammation and epithelial damage in swimmers and cold-air athletes. Eur Respir $\mathrm{J}$ 2009;33:740-6.

58. Sue-Chu M, Karjalainen EM, Altraja A, et al. Lymphoid aggregates in endobronchial biopsies from young elite cross-country skiers. Am J Respir Crit Care Med 1998:158:597-601.

59. Park C, Stafford C, Lockette W. Exercise-induced asthma may be associated with diminished sweat secretion rates in humans. Chest 2008:134:552-8. 
60. Knöpfli BH, Bar-Or 0. Vagal activity and airway response to ipratropium bromide before and after exercise in ambient and cold conditions in healthy cross-country runners. Clin J Sport Med 1999:9:170-6.

61. Knöpfli BH, Bar-Or 0, Araújo CG. Effect of ipratropium bromide on EIB in children depends on vagal activity. Med Sci Sports Exerc 2005;37:354-9.

62. Freishtat RJ, Watson AM, Benton AS, et al. Asthmatic airway epithelium is intrinsically inflammatory and mitotically dyssynchronous. Am J Respir Cell Mol Biol 2011;44:863-9.

63. Adir Y, Shupak A, Gil A, et al. Swimming-induced pulmonary edema: clinical presentation and serial lung function. Chest 2004;126:394-9.

64. Koehle MS, Lepawsky M, McKenzie DC. Pulmonary oedema of immersion. Sports Med 2005:35:183-90.

65. Young AJ, Castellani JW, O'Brien C, et al. Exertional fatigue, sleep loss, and negative energy balance increase susceptibility to hypothermia. J Appl Physiol 1998;85:1210-17.

66. Castellani JW, Young AJ, Degroot DW, et al. Thermoregulation during cold exposure after several days of exhaustive exercise. J Appl Physiol 2001;90:939-46.

67. Young AJ, Castellani JW. Exertional fatigue and cold exposure: mechanisms of hiker's hypothermia. Appl Physiol Nutr Metab 2007;32:793-8.

68. Schwindt CD, Zaldivar F, Eliakim A, et al. Inhaled fluticasone and the hormonal and inflammatory response to brief exercise. Med Sci Sports Exerc 2010;42:1802-8.

69. Hancox RJ, Subbarao P, Kamada D, et al. Beta2-agonist tolerance and exercise induced bronchospasm. Am J Respir Crit Care Med 2002:165:1068-70.

70. World Anti-Doping Agency. Therapeutic Use Exemptions. International Standard for Therapeutic Use Exemptions (ISTUE). http://www.wada-ama.org/ en/Science-Medicine/TUE/ (accessed 16 February 2012).

71. Bärtsch $\mathbf{P}$, Saltin B, Dvorak J. Consensus statement on playing football at different altitude. Scand J Med Sci Sports 2008;18 Suppl 1:96-9.

72. Fulco CS, Rock PB, Cymerman A. Maximal and submaximal exercise performance at altitude. Aviat Space Environ Med 1998;69:793-801.

73. Péronnet $\mathbf{F}$, Thibault G, Cousineau DL. A theoretical analysis of the effect of altitude on running performance. J Appl Physiol 1991:70:399-404.

74. Brosnan MJ, Martin DT, Hahn AG, et al. Impaired interval exercise responses in elite female cyclists at moderate simulated altitude. J Appl Physiol 2000;89:1819-24.

75. Chapman RF, Stickford JL, Levine BD. Altitude training considerations for the winter sport athlete. Exp Physiol 2010;95:411-21.

76. Roach RC, Koskolou MD, Calbet JA, et al. Arterial 02 content and tension in regulation of cardiac output and leg blood flow during exercise in humans. Am J Physiol 1999;276:H438-45

77. Calbet JA, Lundby C. Air to muscle 02 delivery during exercise at altitude. High Alt Med Biol 2009;10:123-34

78. Calbet JA, Lundby C, Koskolou M, et al. Importance of hemoglobin concentration to exercise: acute manipulations. Respir Physiol Neurobiol 2006;151:132-40.

79. Suarez J, Alexander JK, Houston CS. Enhanced left ventricular systolic performance at high altitude during Operation Everest II. Am J Cardiol 1987;60:137-42.
80. Calbet JA, Robach P, Lundby C. The exercising heart at altitude. Cell Mol Life Sci 2009;66:3601-13.

81. Chapman RF, Stager JM, Tanner DA, et al. Impairment of 3000-m run time at altitude is influenced by arterial oxyhemoglobin saturation. Med Sci Sports Exerc 2011:43:1649-56.

82. Hackett PH, Roach RC. High-altitude illness. N Engl J Med 2001;345:107-14.

83. Bartsch P, Bailey DM, Berger MM, et al. Acute mountain sickness: controversies and advances. High Alt Med Biol 2004;5:110-24.

84. Bärtsch P, Saltin B. General introduction to altitude adaptation and mountain sickness. Scand J Med Sci Sports 2008;18 Suppl 1:1-10.

85. Bailey DM, Roukens $\mathrm{R}$, Knauth M, et al. Free radical-mediated damage to barrier function is not associated with altered brain morphology in high-altitude headache. J Cereb Blood Flow Metab 2006;26:99-111.

86. Schommer K. Wiesegart N, Menold E, et al. Training in normobaric hypoxia and its effects on acute mountain sickness after rapid ascent to $4559 \mathrm{~m}$. High Alt Med Biol 2010;11:19-25.

87. Brugniaux JV, Schmitt L, Robach P, et al. Living high-training low: tolerance and acclimatization in elite endurance athletes. Eur J Appl Physiol 2006;96:66-77.

88. Basnyat B Murdoch DR. High-altitude illness. Lancet 2003:361:1967-74

89. Schuler B, Thomsen JJ, Gassmann M, et al. Timing the arrival at 2340 m altitude for aerobic performance. Scand J Med Sci Sports 2007:17:588-94.

90. Gore CJ, McSharry PE, Hewitt AJ, et al. Preparation for football competition at moderate to high altitude. Scand J Med Sci Sports 2008:18 Suppl 1:85-95.

91. Levine BD, Stray-Gundersen J. 'Living high-training low': effect of moderatealtitude acclimatization with low-altitude training on performance. J Appl Physiol 1997;83:102-12

92. Pfitzinger P, Beck K. Guide to high-altitude training. Intelligent Training for Distance Runners. http://www.pfitzinger.com/hat.shtml laccessed 20 February 2012)

93. Julian CG, Gore CJ, Wilber RL, et al. Intermittent normobaric hypoxia does not alter performance or erythropoietic markers in highly trained distance runners. J Appl Physiol 2004:96:1800-7.

94. Tadibi V, Dehnert C, Menold E, et al. Unchanged anaerobic and aerobic performance after short-term intermittent hypoxia. Med Sci Sports Exerc 2007;39:858-64

95. Rodríguez FA, Truijens MJ, Townsend NE, et al. Performance of runners and swimmers after four weeks of intermittent hypobaric hypoxic exposure plus sea level training. J Appl Physiol 2007:103:1523-35.

96. Siebenmann C, Robach P, Jacobs RA, et al. 'Live high-train low' using normobaric hypoxia: a double-blinded, placebo-controlled study. J Appl Physiol 2012;112:106-17.

97. Centres for Disease Control and Prevention. Nonfatal sports and recreation heat illness treated in hospital emergency departments - United States, 2001-2009. Morb Mortal Wkly Rep 2011;60:977-80

98. Mueller F, Colgate B. Annual Survey of Football Injury Research, 1931-2009. National Center for Catastrophic Injury Research. http://www.unc.edu/depts/ nccsi/ (accessed: 20 February 2012).

99. Rae DE, Knobel GJ, Mann T, et al. Heatstroke during endurance exercise: is there evidence for excessive endothermy? Med Sci Sports Exerc 2008;40:1193-204. 